\title{
Cytochemical and Haematological Studies in Leukemia Patients, Its Appraisal in Classification and Clinical Course of Leukemia
}

\author{
Alpana Chouhdary ${ }^{1}$, Alok Choudhary ${ }^{2}$ \\ ${ }^{1}$ Assistant Professor (Department of Pathology, JNU. Institute For \\ Medical Sciences and Research Centre, Jaipur, India.) \\ ${ }^{2}$ Consultant Paediatrician (Rajgovind Child Clinic, Jaipur, India.)
}

\section{Introduction}

The term leukemia was first coined by Virchow in 1847 and later he distinguished two forms of leukemias, on in which splenomegaly predominates and another in which lymphadenopathy is most prominent. Leukemia is a morbid condition of unknown etiology and fatal termination which is characterized by widespread proliferation of leukocytes and their precursors in the tissues of body and usually associated with qualitative and quantitative changes in circulating white cells of the blood. The high incidence of AML is seen in adults, accounting for almost $80 \%$ of acute leukemia in adults and only $20 \%$ of acute leukemias in children [1] In patients with acute myeloid leukemia (AML), the median age is about seventy years [2] the majority of studies have found great occurrence of AML in males, constituting a male to female ratio of 2.5:1[3]. In 2013, males have been accounted for more than 57 percent of the new cases of leukemia [4]. Acute Myeloid Leukemia (AML) is actually a varied selection of wide number of malignant neoplastic diseases that may be grouped on the basis of morphological cytogenetic and also with molecular and genetics criteria [5].

The developing countries have greater burden of cancer including haematological malignancies due to population growth, aging and urbanization, changing dietary habits, better control of infections and increasing tobacco consumption [6]. The aim of this study is to diagnose and classify leukemia and to evaluate the role of some Cytochemical stains namely MPO, SBB, NSE and PAS in diagnosis of majority of leukemias.

These two tables give the general pattern of Cytochemical staining in AML and ALL.

General Pattern of Cytochemical staining in AML

\begin{tabular}{|l|l|l|l|l|l|l|l|}
\hline Stains & M1 & M2 & M3 & M4 & M5 & M6 & M7 \\
\hline Myeloperoxidase & +ve & +ve & +ve & +ve & -ve & +ve & -ve \\
\hline Sudan black -B & +ve & +ve & +ve & +ve & -ve & +ve & -ve \\
\hline PAS & $+\mathrm{ve}$ & +ve & -ve & $-\mathrm{ve}$ & +ve & $+\mathrm{ve}$ & +ve \\
\hline
\end{tabular}

General Pattern of Cytochemical staining in ALL

\begin{tabular}{|l|l|l|l|}
\hline Stain & L1 & L2 & L3 \\
\hline Myeloperoxidase & -ve & -ve & -ve \\
\hline Sudan black -B & -ve & -ve & -ve \\
\hline Periodic acid Schiff & $+\mathrm{ve}(70 \%)$ & $+\mathrm{ve}(70 \%)$ & $-\mathrm{ve}$ \\
\hline
\end{tabular}

II. Material And Methods

The present study was carried out on 117 patients over a span of two years. A Detailed history and physical examination pertaining to leukemia was obtained in each case. Diagnosis of type of leukemia was established on the basis of clinical data, the hematologic findings, morphologic appearance of the abnormal cells and cytochemistry. Few cases in remission and others in relapse were also investigated.

Estimation of hemoglobin, volume of packed red cells, total leukocyte count, platelet count were done by three part cell counter Sysmex XP-100. Smears were stained with Leishman's stain and differential count was done by counting 200 cells. The general blood picture was also recorded. Bone marrow examination was done when required. Cytochemical stains - Myeloperoxidase, Sudan Black B, Periodic acid Schiff (PAS) and Non Specific Esterase was done as and when required. All the Cytochemical stains were prepared by conventional methods.

\section{Results}

The present study is based on 117 cases of leukemias. Proper clinical examination of patients, General Blood Picture, Bone marrow examination and Cytochemical staining was done. 
Table 1 :Types of leukemia studied

\begin{tabular}{|l|l|l|}
\hline Type & No. of cases & Percentage \\
\hline Acute lymphoblastic leukemia (ALL) & 23 & 19.65 \\
\hline Acute myeloid leukemia (AML) & 38 & 32.47 \\
\hline Chronic myeloid leukemia (CML) & 35 & 29.91 \\
\hline Chronic lymphoblastic leukemia (CLL) & 09 & 07.69 \\
\hline Acute undifferentiated leukemia (AUDL) & 12 & 10.25 \\
\hline Total cases & 117 & 100.00 \\
\hline
\end{tabular}

This table shows commonest leukemia was AML (32\%) followed by in decreasing order:

CML $(29.91 \%)>\operatorname{ALL}(19.85 \%)>\operatorname{CLL}(07.69 \%)$

Table 2 :Age distribution in different leukemia

\begin{tabular}{|c|c|c|c|c|c|c|c|c|c|c|c|c|}
\hline \multirow[t]{2}{*}{ Age group } & \multicolumn{2}{|l|}{ ALL } & \multicolumn{2}{|c|}{ AML } & \multicolumn{2}{|c|}{ CML } & \multicolumn{2}{|c|}{ CLL } & \multicolumn{2}{|c|}{ AUDL } & \multicolumn{2}{|c|}{$\begin{array}{l}\text { Total \% and } \\
\text { number of cases }\end{array}$} \\
\hline & No. & $\%$ & No. & $\%$ & No. & $\%$ & No. & $\%$ & No. & $\%$ & No. & $\%$ \\
\hline $0-10$ & 16 & 69.4 & 04 & 10.5 & 02 & 5.7 & - & - & 01 & 8.3 & 23 & 19.65 \\
\hline $11-20$ & 02 & 08.7 & 10 & 26.3 & 05 & 14.2 & - & - & 03 & 25. & 20 & 17.09 \\
\hline $21-30$ & 02 & 08.7 & 11 & 28.9 & 10 & 28.5 & - & - & 04 & 33.3 & 27 & 23.07 \\
\hline $31-40$ & 02 & 08.7 & 07 & 18.42 & 04 & 11.4 & - & - & - & - & 13 & 11.11 \\
\hline $41-50$ & - & - & 02 & 05.2 & 07 & 20.0 & 02 & 22.2 & 02 & 16.6 & 13 & 11.11 \\
\hline $51-60$ & - & - & 02 & 05.2 & 04 & 11.4 & 05 & 55.2 & 02 & 16.6 & 13 & 11.11 \\
\hline $\begin{array}{l}61-70 \\
\text { And above }\end{array}$ & 01 & 04.3 & 02 & 05.2 & 03 & 8.5 & 02 & 22.2 & - & - & 08 & 6.83 \\
\hline
\end{tabular}

This table shows Commonest age group affected by leukemia was $3^{\text {rd }}$ decade of life $(27 \%)$ followed by first decade of life $19 \%$.

Table 3: Sex distribution

\begin{tabular}{|l|l|l|l|l|}
\hline Type of leukemia & \multicolumn{2}{|c|}{ Male } & \multicolumn{2}{c|}{ Female } \\
\hline & No. & $\%$ & No. & $\%$ \\
\hline CLL (09) & 07 & 77.78 & 02 & 22.22 \\
\hline ALL(23) & 15 & 65.21 & 08 & 34.79 \\
\hline CML(35) & 26 & 74.28 & 09 & 25.72 \\
\hline AML(38) & 29 & 76.31 & 09 & 23.69 \\
\hline AUDL (12) & 09 & 75.00 & 03 & 25.00 \\
\hline Total (117) & 86 & 73.50 & 31 & 26.50 \\
\hline
\end{tabular}

Male to Female ratio $=2.77: 1$.

Table 4: Clinical signs

\begin{tabular}{|l|l|l|l|l|l|l|l|l|l|l|}
\hline \multirow{2}{*}{ Signs } & \multicolumn{2}{|l|}{ CLL (9) } & \multicolumn{2}{|l|}{ ALL(23) } & \multicolumn{2}{l|}{ AML (38) } & \multicolumn{2}{l|}{ CML(35) } & \multicolumn{2}{c|}{ AUDL (12) } \\
\cline { 2 - 11 } & No. & $\%$ & No. & $\%$ & No. & $\%$ & No. & $\%$ & No. & $\%$ \\
\hline Sternal Tenderness & - & - & 14 & 60.80 & 18 & 47.36 & 23 & 65.71 & 4 & 33.3 \\
& & & & & & & & & & 0 \\
\hline Gum Hypertrophy & - & - & - & - & 1 & 2.63 & - & - & 1 & 8.33 \\
\hline
\end{tabular}

Hepatomegaly $($ Total cases $=54)=50.42 \%$

\begin{tabular}{|l|l|l|l|l|l|l|l|l|l|l|}
\hline 2 finger & - & - & 3 & 13.00 & - & - & 7 & 20.00 & - & - \\
\hline 3 finger & - & - & 14 & 60.80 & 8 & 21.00 & - & - & - & - \\
\hline 4 finger or more & - & - & - & - & 19 & 50.00 & - & - & 8 & 66.50 \\
\hline
\end{tabular}

$* *$ Splenomegaly $($ Total cases $=70)=59.82 \%$

\begin{tabular}{|l|l|l|l|l|l|l|l|l|l|l|}
\hline Mild & 3 & 30.00 & 1 & 4.34 & 4 & 10.50 & 1 & 2.50 & - & - \\
\hline Moderate & - & - & 14 & 60.80 & 11 & 28.90 & 29 & 82.80 & 7 & 58.30 \\
\hline Massive & - & - & - & - & - & - & 5 & 14.20 & - & - \\
\hline
\end{tabular}

Lymphadenopathy (Total cases $=46)=39.31 \%$

\begin{tabular}{|l|l|l|l|l|l|l|l|l|l|l|}
\hline Cervical & 1 & 11.00 & - & - & 4 & 10.50 & 3 & 8.50 & 1 & 8.33 \\
\hline Axillary & - & - & - & - & - & - & - & - & - & - \\
\hline Generalize & 4 & 44.4 & 17 & 73.9 & 25 & 65.70 & - & - & 7 & 58.30 \\
\hline
\end{tabular}

Table 5: Hematological findings

\begin{tabular}{|l|l|l|l|l|l|l|l|l|l|l|l|}
\hline $\begin{array}{l}\text { Hematological } \\
\text { Findings }\end{array}$ & Range & \multicolumn{2}{l|}{ CLL(9) } & \multicolumn{2}{l|}{ ALL(23) } & \multicolumn{3}{l|}{ CML(35) } & \multicolumn{2}{l|}{ AUDL (12) } \\
\hline & & No & $\%$ & No & $\%$ & No & $\%$ & No & $\%$ & No & $\%$ \\
\hline Hemoglobin & $<$ & 1 & 11.10 & 6 & 26.10 & 4 & 11.42 & 28 & 73.68 & 8 & 66.60 \\
\hline
\end{tabular}


Cytochemical and Haematological Studies In Leukemia Patients, Its Appraisal In Classification...

\begin{tabular}{|c|c|c|c|c|c|c|c|c|c|c|c|}
\hline \multicolumn{12}{|l|}{$(\mathrm{gm} \%)$} \\
\hline & $5-8$ & 2 & 22.20 & 14 & 60.68 & 26 & 74.28 & 7 & 18.42 & 4 & 33.40 \\
\hline & $>8$ & 6 & 66.60 & 3 & 13.04 & 5 & 14.28 & 3 & 7.89 & - & - \\
\hline \multirow{4}{*}{$\begin{array}{l}\text { Platelet count } \\
(1000 / \mathrm{ml}\end{array}$} & $>50$ & - & - & 11 & 47.80 & 3 & 8357 & 17 & 44.73 & 4 & 33.30 \\
\hline & $50-100$ & - & - & 6 & 26.08 & - & - & 10 & 26.31 & 3 & 25.00 \\
\hline & $101-151$ & 6 & 66.60 & 4 & 17.39 & - & - & 10 & 26.31 & 3 & 41.60 \\
\hline & $>500$ & - & - & - & - & 15 & 42.85 & - & - & - & - \\
\hline \multirow{4}{*}{$\begin{array}{l}\text { Total } \\
\text { leucocyte } \\
\text { count } \\
(1000 / \mathrm{ml}) \\
\end{array}$} & $>4$ & - & - & 4 & 17.30 & - & - & 2 & 5.26 & 2 & 16.60 \\
\hline & 4-12 & 2 & 22.20 & 4 & 17.60 & 1 & 2.85 & 2 & 5.26 & - & - \\
\hline & $13-30$ & - & - & 4 & 17.30 & 3 & 8.57 & 22 & 57.89 & 2 & 16.60 \\
\hline & $>30$ & 7 & 77.78 & 13 & 56.52 & 31 & 88.57 & 12 & 31.57 & 8 & 66.60 \\
\hline
\end{tabular}

Table 6: Subtype of acute leukemias

\begin{tabular}{|c|c|c|c|c|}
\hline \multirow{2}{*}{$\begin{array}{l}\text { Type } \\
\text { ALL }\end{array}$} & Total No. & Subtypes & No. of cases & Percentage \\
\hline & 23 & $\begin{array}{l}\text { L1 } \\
\text { L2 } \\
\text { L3 }\end{array}$ & $\begin{array}{l}13 \\
10 \\
-\end{array}$ & $\begin{array}{l}56.52 \\
43.48 \\
-\end{array}$ \\
\hline AML & 38 & $\begin{array}{l}\mathrm{M}_{0} \\
\mathrm{M}_{1} \\
\mathrm{M}_{2} \\
\mathrm{M}_{3} \\
\mathrm{M}_{3 \mathrm{a}} \\
\mathrm{M}_{4} \\
\mathrm{M}_{4 \mathrm{E}} \\
\mathrm{M}_{5 \mathrm{a}} \\
\mathrm{M}_{\mathrm{b}} \\
\mathrm{M}_{6} \\
\mathrm{M}_{7}\end{array}$ & $\begin{array}{l}- \\
10 \\
21 \\
3 \\
1 \\
- \\
2 \\
- \\
- \\
- \\
-\end{array}$ & $\begin{array}{l}26.31 \\
55.26 \\
7.89 \\
2.63 \\
- \\
2.60 \\
- \\
5.26 \\
- \\
-\end{array}$ \\
\hline
\end{tabular}

This table shows that in ALL, $\mathrm{L}_{1}(56.52 \%)$ was the most common subtype and in AML , $\mathrm{M}_{2}(55.26 \%)$ was the most common subtype.

Table 7: Differential count in CML (general blood picture)

\begin{tabular}{|c|c|c|c|}
\hline Cells & Range & No. of cases (35) & Percentage \\
\hline \multirow[t]{4}{*}{ Blast } & $0-1$ & 5 & 14.28 \\
\hline & $2-10$ & 20 & 57.14 \\
\hline & $11-20$ & 7 & 20.00 \\
\hline & $>20$ & 3 & 7.58 \\
\hline \multirow[t]{4}{*}{ Promyelocytes } & $0-1$ & 1 & 2.82 \\
\hline & $2-10$ & 20 & 57.15 \\
\hline & $11-20$ & 13 & 37.15 \\
\hline & $>20$ & 1 & 2.8 \\
\hline \multirow[t]{3}{*}{ Myelocytes } & $5-15$ & 8 & 22.85 \\
\hline & $16-30$ & 22 & 62.85 \\
\hline & $>30$ & -5 & 14.40 \\
\hline \multirow[t]{3}{*}{ Metamyelocytes } & $5-15$ & 4 & 11.42 \\
\hline & $16-30$ & 25 & 71.43 \\
\hline & $>30$ & 6 & 17.15 \\
\hline \multirow[t]{5}{*}{ Neutrophils(band) } & $0-1$ & 1 & 2.87 \\
\hline & $2-10$ & 1 & 2.87 \\
\hline & $11-20$ & 3 & 7.58 \\
\hline & $21-30$ & 18 & 51.42 \\
\hline & $>30$ & 12 & 34.58 \\
\hline \multirow[t]{3}{*}{ Basophils } & $0-1$ & 23 & 65.72 \\
\hline & 2.5 & 12 & 34.28 \\
\hline & $>5$ & - & - \\
\hline
\end{tabular}

This table shows that in GBP 2-10 blasts were seen in $57.14 \%$, 2-10 promyelocytes were seen in $57.15 \%, 16-30$ myelocytes were seen in 62.85\%,16-30 metamyelocytes were seen in71.43\%, 21-30 neutrophils(band) were seen in $51.42 \%$ and $0-1$ basophils were seen in $65.72 \%$ cases. Indicating that metamyelocytes are the most encountered cell found in CML in GBP. 
Cytochemical and Haematological Studies In Leukemia Patients, Its Appraisal In Classification...

\begin{tabular}{|c|c|c|c|c|c|c|c|c|}
\hline \multirow[t]{2}{*}{ Stains } & \multicolumn{2}{|l|}{ ALL } & \multicolumn{2}{|c|}{ AML } & \multicolumn{2}{|c|}{$\begin{array}{l}\text { CML (Blast crises) (n } \\
=6)\end{array}$} & \multicolumn{2}{|c|}{ CLL $(\mathrm{N}=4)$} \\
\hline & $+\mathrm{ve}$ & $\%$ & $+\mathrm{ve}$ & $\%$ & $+\mathrm{ve}$ & $\%$ & $+\mathrm{ve}$ & $\%$ \\
\hline PAS & 17 & 100 & 03 & 23 & 01 & 17 & 01 & 25 \\
\hline SBB & 01 & 6 & 12 & 92 & 06 & 100 & 0 & 0 \\
\hline MPO & 0 & 0 & 12 & 92 & 06 & 100 & 0 & 0 \\
\hline NSE & 0 & 0 & 03 & 23 & 0 & 0 & 0 & 0 \\
\hline
\end{tabular}

\section{Discussion}

The present study is comprised of 117 leukemia patients over a span of two years.

Incidence:The incidence of various types of leukemia's in this study were as follows: AML constituted the commonest type (32.47\%) followed by in order of frequency were CML (29.92\%) > ALL(19.65) $>\operatorname{AUDL}(10.25)>\operatorname{CLL}(7.69)$. leukemic incidence in and around northern India were documented by P.S. Ghalout et al [7]. However in our study AML predominated whereas AML and CML in their study. This may be because of lesser number of cases in our study. In matter of fact in various Indian studies CML varied from $16.4 \%$ to $82 \%$ of all leukemia's (P.S. Ghalout et al 1995).

Age distribution: Over all, maximum cases of leukemia (23\%) were found in $3^{\text {rd }}$ decade of life followed by in order of frequency were $1^{\text {st }}$ decade $(19.65 \%)>2^{\text {nd }}$ decade $(17.09 \%)>4^{\text {th }}, 5^{\text {th }}$ and $6^{\text {th }}$ decade $(11.11 \%)$ each $)>7^{\text {th }}$ decade $(6.83 \%)$ of life. ALL was most common in $1^{\text {st }}$ decade $(69.5 \%)$ of life whereas AML predominant in $3^{\text {rd }}$ decade $(28.9 \%)$ of life followed by $2^{\text {nd }}$ and above 40 years of age it constituted only $15 \%$. Similar observation were reported by Oski, Nathan : P.S. Ghalout et al [8].Amongst chronic leukemia's CML was commonest in $3^{\text {rd }}$ decade $(18.9 \%)$ of life followed by $4^{\text {th }}$ decade $(20 \%)$. CLL were seen those earlier reported by Spier et al [9].

Sex Distribution: As reported by various workers (Gunz et al : P.S. Ghalout et al , : Earle A.M. et al : Segi et al[10] in our study also male cases predominated as compared to females in the whole group of leukemias. The overall male: female ratio in this study was 2.77:1. In AML this ratio was 3.22:1, in ALL $1.87: 1$ and in CLL - 3.50:1

ALL:

Clinical Presentation: Weakness (86\%), anorexia (70\%) and fever $(65.2 \%)$ were the commonest clinical presentation in our study. Petechial hemorrhages (39\%) and bony pain (63\%) were the next complaints of our patients. Similar complaints were documented by Pui C-H et al [11] in their study. Amongst the signs anaemia $(100 \%)$ followed by lymphadenopathy $(73.9 \%)$. hepatomegaly $(73.8 \%)$ splenomegaly $(65.14 \%)$ and sternal tenderness $(60.8 \%)$ were the commonest findings. These findings in our study are similar to those reported earlier in the literature (Weisdrof et al)[12].

Haematological Findings: Total leucocytes count in range of above 30 thousand/ $\mathrm{mm} 3$ were observed in 56.62 cases while $17.3 \%$ cases showed count within range of 13-30 thousand/ mm3. Platelet count were below $<150$ thousand $/ \mathrm{mm} 3$ in $91.30 \%$ cases and $47.8 \%$ of cases even below 50 similar findings were documented by Dahi et al . Choi et al, Weisdrof et al [12-14].

Bone marrow smear examination revealed blast count $>80 \%$ cells in $86.95 \%$ of cases and in $13 \%$ of cases range was $51-80 \%$ cells.

Subtyping : Amongst the all ALL Cases $\mathrm{L}_{1}$ Subtype was commonest $(56.52 \%)$ followed by $\mathrm{L}_{2}$ (43.48\%). No case of $\mathrm{L}_{3}$ subtype was seen. Five large series of studies conducted by keleti et al [15]. Coccia , Hann et al [16], Viana [17], Bennett et al [18] came out with similar findings.

Cytochemistry : Sudan black, Myeloperoxidase and PAS staining were carried out in 17 cases of ALL (no. 94, 22, 19, 02, 111, 105, 117, 40 (++) level but not a single case was +++ level positive. Which brought difficulty in labeling these cases as ALL. On top of that one case showed mild sudan black +ve reaction also. But all these cases were myeloperoxidase negative, which was taken in account for labelling these cases as ALL. Flandrin [19], Scott [20] also observed similar results. These different levels of positive ranging from $0 \nmid 0$ ++ are very peculiar of PAS reaction as observed by Hammuda \& Hayhoe[21].

AML

Clinical Presentation : Commonest presenting complaints of our patients were weakness $(100 \%)$ followed by fever $(92.1 \%)>$ anorexia $(89.47 \%)>$ bony pain $(60.5 \%)>$ abdominal pain $(50 \%)>$ petechial hemorrhages (36.8\%) > Epistaxis (21\%) which are similar to those described by Choi et al [14].

Presenting signs documented by choi et al (1976) are similar as in our patients like pallor (100\%) followed by lymphadenopathy $(76.2 \%)>$ hepatomegaly $(71 \%)>$ sterna tenderness $(47 \%)$. One case of AML presented with gum hyperplasia and gum bleeding. 
Hematological findings: Maximum (57.89\%) AML cases had total leucocyte count in range of $13-30$ thousand/ $\mathrm{mm} 3$ and $31.57 \%$ cases with count $>30$ thousand/mm3. 5.26\% cases came with leucopenia (count $<4000 / \mathrm{mm} 3$ ). $97.36 \%$ cases of AML showed platelet count $<150$ thousand.mm3 and in $44.73 \%$ cases even below 50 thousand/mm3. These findings are similar documented by Dhal et al [13], Choi et al [14], Weisdrof et al [12].

Subclassification : Distribution of AML subtypes in our study were as follows : in order of frequency $\mathrm{M}_{2}(52.62 \%)>\mathrm{M}_{1}(26.31 \%)>\mathrm{M}_{3}(10.92 \%)>\mathrm{M}_{5}(5.26 \%)>\mathrm{M}_{4}(2.6 \%)$. These data corresponds to those given by whittaker [22], Enok [23], Sultan [24] and data from National Institute of cancer.

The difference lies in the incidence of $\mathrm{M}_{4}$ subtype which is very low in our study, this may be due to lesser number of total cases in our study.

Cytochemistry : Mild PAS positivity, (+) level was seen (in case no. $76-\mathbf{M}_{2}$ and case No. $10-\mathbf{M}_{1}$ ) but these were labeled AML because of strong myeloperoxidase and sudan black positivity. Diffuse positivity was also observed. These observations were same as those by Hayhoe[25], Flandrin[19]. Sudan black and myeloperoxidase reaction in AML cases showed positivity in $73 \%$ of blast cells. Similar findings were shown by Hayhoe et al[25] and Flandrin [19]. NSE in AML cases showed positivity (Jane et al)[26]. NSE is stain of monocytic elements (M4 and M5). In our study it showed low diagnostic performance in the staining of monoblasts, it was also positive in some ALL cases. These results go with those of Sharma P et al[27] who found positive staining with NSE in some patients with acute lymphoblastic patients.

CML

Clinical Presentation: These patients main complaints were weakness $(88.5 \%)$ and abdominal pain $(60 \%)$. Among the prominent signs splenomegaly (100\%) pallor $(88.5 \%)$ and sternal tenderness $(65,71 \%)$ which are same as documented by Cortes et al [28].

Hematological Findings: In CML 88\% cases showed total leucocyte count $>30$ thousand/mm3. 42\% of cases: presented with platelet count $>500$ thousand/mm3, $48.57 \%$ cases platelet count were in range of 101 to 500 thousand $/ \mathrm{mm} 3$. 3cases showed count $<50$ thousand $/ \mathrm{mm} 3$ as they were in blast crisis. These mentioned finding are similar to the observation documented by witts et al [29] Kantarji et al[30], Kattlove et al [31] and cheson et al [32]. One of the CML in blast crisis showed diffuse PAS positivity but it was strongly +ve with myeloperoxidase and sudan black. 11 cases of CML in blast crisis showed myeloperoxidase and sudan black positivity.

\section{CLL}

Clinical Presentation: $80 \%$ of patients presented with weakness, $66 \%$ anorexia and $22.2 \%$ with fever. On examination, $80 \%$ revealed pallor, $55 \%$ lymphadenopathy and $30 \%$ cases showed splenomegaly.

Hematological: $77.7 \%$ of CLL patient showed TLC > 30 thousand/mm3 and two patients in range of 4-12 thousand/mm3. All cases of CLL showed platelet count within normal range but 5 cases were in borderline for thrombocytopenia. All these findings are similarly documented by Pangalis et al [33], Witts et al [29].

\section{Conclusion}

Study of 117 cases of different leukemia gave following outcomes.

- Commonest form of leukemia was AML (32.47\%) followed by CML (29.91\%) and ALL (19.65\%).

- Acute leukemia was common in young age group.

- ALL was commonest in first decade of life (66.5\%).

- CLL was common in $6^{\text {th }}$ decade of life.

- Commonest affected age group for leukemia was $3^{\text {rd }}$ decade of life.

- Male to female ratio of leukemia was 2.77:1

- Abdominal pain was commonest in CML.

- Weakness and fever were commonest in acute leukemia.

- Pallor, sternal tenderness and petechial haemorrhage were commonest signs of acute leukemia .

- Splenomegaly was predominant sign in CML.

- Thrombocytopenia was common in acute leukemias.

- $\mathrm{L}_{1}$ subtype was commonest in ALL (56.52\%).

- $\mathrm{L}_{3}$ subtype was least common in $\operatorname{ALL}(0 \%)$.

- $\mathrm{M}_{2}$ was predominant subtype observed in AML(55.26).

- Almost all cases of ALL showed PAS positivity though of diffused type.

- All AML cases except $M_{5 b}$ showed Sudan and myeloperoxidase positivity. 
In brief, it can be concluded that by the help of Leishman's stain and other clinical criteria, we can diagnose and classify majority of leukemias.

Results obtained by PAS stains are very variable. Only PAS positivity is not sole criterion for diagnosing ALL. To establish ALL absolute myeloperoxidase negativity along with PAS positivity can be taken in to account. In many occasions Sudan black gives very faint positive reaction in AML. In such cases myeloperoxidase positivity is considered to be reliable.

So the best method to differentiate between lymphoblastic and myeloblastic origin of acute leukemia is combined use of PAS and myeloperoxidase.

Hence, even though morphology and Cytochemistry are the gold standards and play a vital role in the accurate diagnosis of leukemias, but the use of the recent techniques like flowcytometry and cytogenetics is essential in difficult cases. But they are costly so it is practically difficult to use these tests for the masses.

\section{Acknowledgements}

I am very grateful to my brother in law Ankit choudhary for typing this manuscript on a short notice, without his co-operation it would not have been possible for me to complete this work.

Joyes Daniel, Radha saini, Sandeep for their constant support throughout the work.

Conflict of interest :-No

\section{References}

[1]. American Cancer Society : Cancer Facts and Figures (2016) Atlanta, Ga : American Cancer Society.

[2]. Ossenkoppele G, Lowenberg B (2015) How I treat the older patient with acute myeloid leukemia. Blood 125: $764-774$

[3]. Belson M, Kingsley B, Holmes A (2007) Risk factors for acute leukemia in children : A review. Environmental Health Perspectives 115: $138-145$.

[4]. American Cancer Society : Cancer Facts and Figures (2013) Atlanta, Ga : American Cancer Society.

[5]. His ED (2012) Pathologic and molecular genetic features of chronic lymphocytic leukemia. Seminares in Oncolog 39: 74-79.

[6]. Rathee R, Vashist M, Kumar A, Singh S (2014) Incidence of Acute and Chronic Forms Of Leukemia In Haryana. Int J Pharm PharmSci 6: $323-325$

[7]. .P S Gahlout,Sood A K,Malhotra RC,Yadav SP and Mittal A.Pattern of leukemia in northern India.Indians J.Hematol.Blood transf 1995; xiii(2):73-77.

[8]. Oski and Nathan (from text - Hematology of Infancy and childhood).

[9]. Spier CM, Kjeldsberg CR, Headd DR. Chronic lymphocytic leukemia in young adults. Am J Clin pathol 1985;84:675-678.

[10]. Segi M, Kurihara M, Cancer mortality for selected site in 24 countries. No. 4 (1962-63). Soudai Department Publ. Health Tohoku. University School of Medicine 1966.

[11]. Pui C-H stass S, Green A. Bone marrow necrosis in children with malignant disease. Cancer 1985;56:1522.

[12]. Weidsorf D.J., Oken M.M. Chronic myelodysplastic syndrome: Short survival with or without evolution of acute leukemia. Br. Implications. Br. J. Haemat 1984;68:189.

[13]. Dahl GV, Kalwinsky DK. Allogenic bone marrow transplantation in program of intensive sequential chemotherapy for children and young adult with acute nonlymphocytic leukemia in first remission. J. Clin. Oncol 1990;8:925.

[14]. Choi SI and Simone JV. Acute nonlymphocytic leukemia in 171 children. Med Pediatr Oncol 1976;2:119.

[15]. Keleti, J., Revesz. T. And Schuler, D. Morphological diagnosis in childhood leukaemia. Br. J. Haemat 1978;40:501-50.

[16]. Hann, I.M., Evans, D.I.K., Palmer, M.K., Morris, Jones, P.J. and Haworht C. The prognostic significance of morphological features in childhood acute lymphoblastic leukaemia. Clin. Lab. Haemat 1979;1:215-226.

[17]. Viana MB, Maurer HS and Ferenc C. Subclassification of acute lymphoblastic leukemia in children: Analysis of the reproducibility of morphological criteria and prognositic implications Br. J Haemat 1980; 44:383-388

[18]. Bennett. J.M., Catovsky, D. The morphological classification of acute lymphoblastic leukemia concordance among observers and clinical correlations. Br. J. Haematol 1981;47:559.

[19]. Flandrin G and Daniel MT. Practical value of cytochemical studies for the classification of acute leukemias. Recent result in cancer Research 1973;43:43-56

[20]. Scott CS. Cytochemical applications in haematology, with particular reference to acute leukemias: A review. Med Lab Sci 1978;35:111-136.

[21]. Hammouda F Quaglino D and Hayhoe FGJ. Blastic crisisof chronic granulocytic leukemia. Cytochemical, Cytogenetic and autoradiographic studies in four cases Brit. Med. J 1964;1:1275.

[22]. Wittaker JA, Withey J, Powell DE, B. Parry TE and Khurshid M. Leukaemia Classification: A study of the accuracy of diagnosis in 456 patients. Br. J. Haemat 1979;41:177-184.

[23]. Enock RE, Bauman AW and Bennett JM. Adult acute leukemia : The Rochester (NY) experience. Arch Int. Med. 1976;136:12561261.

[24]. Sultan C, Deregnaucourt J, Ko YW, Imbert M, Ricard D, Agay MF, Gouault- Heilmann M and Brun B. Distribution of 250 cases of acute myeloid leukemia (AML) according to the FAB classification and response to therapy. Br. J. Haemat 1981;47:545-551.

[25]. Hayhoe, F.G.J The cytochemistry of haemopoiesis. In Britton C.J.C. (ed.) Dsorders of the Blood. Churchill, London 1969;123.

[26]. Jane L Liesveld and Marshal A Lichtman. Morphologic variants of acute myelogenous leukemia. Williams Hematology $7^{\text {th }}$ ed. McGraw Hill 2006.:1191.

[27]. Sharma PI, Tyagi S. NSE/ $\alpha$ NAE positivity in B-lineage acute lymphoblastic leukemia. Biotech Histochem. 2014 Jan; 89(1): 19-22. Jane L Liesveld and Marshal A Lichtman. Morphologic variants of acute myelogenous leukemia. Williams Hematology $7^{\text {th }}$ ed. McGraw Hill 2006.:1191.

[28]. Cortes JE, Talpaz M, Kantarkian H. Chronic Myelogenous leukemia A review. Am J Med 1996;100:555.

[29]. Witts LJ. Blackbur EK, Callender ST. Dacia JV, Davidson WM. Chronic granulocytic leukemia: comparison of radiotherapy and Busulphan therapy. Report of the Medical Research council's working party for theraperutic trials in leukemia. Br. Med J $1968 ; 1: 201$. 
[30]. Kantarjian HM, Dixon D, Keating MJ. Characteristics of accelerated disease in chronic myelogenous leukemia. Cancer 1988;61:1441.

[31]. Kattlove, H.E. Gaucher cells in chronic myelocytic leukemia: An acquired abnormality. Blood 1969; $33: 379$.

[32]. Cheson BD, Bennett, JN, Rai KR. Guideline for clinical: protocols for chronic lymphocytic leukemia, recommendation of the NCIsponsored working group. AJ Hematol 1988;29:152-163.

[33]. Pangalis GA, Nathawani BN, Rappaport H. Malignant lymphoma well differentiated lymphocytic leukemia and macroglobulinemia of waldenstron. Cncer 1977;39:999-1010. 